\title{
Veri Madenciliği ile Türkiye'deki ve Avrupa Birliği Ülkelerindeki Bilgisayar Mühendisliği Programlarının Karşılaştırılması
}

\author{
Seda Kılıçer ${ }^{1,2 *}$, Ruya Samli² \\ $1^{*}$ Beykent Üniversitesi, Bilgisayar Mühendisliği Bölümü, İstanbul, Türkiye, (ORCID: 0000-0002-3464-6219), sedakilicer@beykent.edu.tr \\ 2 İstanbul Üniversitesi-Cerrahpaşa, Bilgisayar Mühendisliği Bölümü, İstanbul, Türkiye, (ORCID: $\underline{0000-0002-8723-1228}$ ), ruyasamli@istanbul.edu.tr
}

(İlk Geliş Tarihi 2 Şubat 2021 ve Kabul Tarihi 26 Mayıs 2021)

(DOI: $10.31590 /$ ejosat.873157)

ATIF/REFERENCE: Kılıçer, S. \& Samli, R. (2021). Veri Madenciliği İle Türkiye'deki Ve Avrupa Birliği Ülkelerindeki Bilgisayar Mühendisliği Programlarının Karşılaştırılması. (25), 120-130.

\section{$\ddot{O} z$}

Veri madenciliği birçok alanda kullanılmaktadır. Veri madenciliği ile amaçlanan insanlar için ilk bakışta bir anlam ifade etmeyen verilerden insanlar için faydalı olabilecek bilgiler elde edilebilmesidir. Bu çalışmada veri madenciliği eğitim alanında kullanılmıştır. Bu çalışmada amaçlanan Türkiye'deki üniversitelerde ve Avrupa Birliği ülkelerindeki üniversitelerde bilgisayar mühendisliği lisans programlarının dersleri veri madenciliği yöntemleriyle sınıflandırılarak birbiriyle karşılaştırılmıştır. Bu karşılaştırma için Türkiye'deki 80 adet üniversitenin bilgisayar mühendisliği lisans ders listeleri ve Türkiye'deki üniversitelerle Erasmus programı anlaşması bulunan Avrupa Birliği ülkelerindeki 29 adet üniversitenin bilgisayar mühendisliği lisans ders listeleri toplanmış ve incelenmiştir. Elde edilen veriler veri madenciliği sınıflandırma algoritmalarından Naive Bayes algoritması ve J48 karar ağacı algoritması kullanılarak Weka platformunda analiz edilmiştir. Derslerin çeşitliliklerinin incelenebilmesi için dersler "Temel Dersler, Matematik Dersleri, Yazılım Dersleri, Donanım Dersleri, Yapay Zeka Dersleri, Ağ Güvenlik Dersleri, Ek Dersler, Bölüm İçi Seçmeli Dersler, Bölüm Dıı̧ı Seçmeli Dersler" olmak üzere 9 tane sınıfa ayrılmıştır. Çalışma sonucunda Türkiye'deki üniversitelerdeki bilgisayar mühendisliği ders çeşitliliğinin Yapay Zeka Dersleri, Ağ Güvenliği Dersleri, Dölüm Dıı̧ı Seçmeli Dersler ve Ek Dersler sınıflarında Avrupa Birliği ülkelerindeki üniversitelerin bilgisayar mühendisliği bölümlerindeki ders çeşitlliğinden fazla olduğu; Matematik Dersleri, Donanım Dersleri, Yazılım Dersleri, Bölüm İçi Seçmeli Dersler ve Temel Dersler sınıflarına ait derslerde ise Avrupa Birliği ülkelerindeki bilgisayar mühendisliği bölümlerinden daha az olduğu görülmüştür. Bu çalışmadaki bir diğer incelenen durum ise derslerin kredileri ile AKTS'lerinin (Avrupa Kredi Transfer Sistemi) kıyaslanmasıdır. Türkiye'deki bilgisayar mühendisliği lisans programlarından ve Avrupa Birliği'ndeki bilgisayar mühendisliği lisans programlarından veri elde edilirken derslerin kredi ve AKTS miktarındaki farklılık dikkat çekmiştir. Bu sebeple belirlenen ders sınıflarına göre kredi ortalamaları hesaplanarak Türkiye'deki derslerin kredi ortalamaları ile Avrupa Birliği'ndeki derslerin kredi ortalamaları karşılaştırılmıştır. Bu çalışma ile Erasmus yapan öğrencilerin Avrupa Birliği'ndeki üniversitelerden aldıkları dersleri Türkiye'deki okuduğu üniversitede eşleştirme sırasında yaşadığı zorluğa da dikkat çekmek hedeflenmiştir.

Anahtar Kelimeler: Veri madenciliği, Karar Ağaçları, Naive Bayes, J48, Eğitim, Bilgisayar Mühendisliği Programı

\section{A Comparison of Computer Engineering Programs in Turkey and European Community Countries by Data Mining}

\begin{abstract}
Using data mining in many areas, it is tried to obtain useful information for people from meaningless data sets. In this study, data mining was used in the education field. This study was a comparison of computer engineering at universities in European Union countries and Turkey intended in the course of classified data mining methods with each other. Erasmus program agreements with 29 pieces of computer engineering university course listings in comparison to the 80 European Union countries with this university computer engineering course listings in Turkey, and these listings have been collected and analyzed. These data obtained were analyzed by Weka platform using Naive Bayes algorithm and J48 decision tree algorithm, which are among data mining classification algorithms. In order to examine the courses, the courses are divided into 9 classes as "Basic Courses, Mathematics Courses, Software Courses, Hardware
\end{abstract}

* Sorumlu Yazar: $\underline{\text { sedakilicer@beykent.edu.tr }}$ 
Courses, Artificial Intelligence Courses, Network Security Courses, Additional Courses, In-Departmental Elective Courses, Non-Departmental Elective Courses". As a result of the study, Artificial Intelligence Courses, Network Security Courses, NonDepartmental Elective Courses, Additional Courses in Turkey are more than just computer engineering departments in European Union countries. It has been observed that the courses of Mathematics Courses, Hardware Courses, Software Courses, Departmental Elective Courses and Basic Courses are less than the computer engineering departments in European Union countries. Another situation examined in this study is the comparison of the credits of the courses. In these courses in Turkey and European Union while acquiring data from undergraduate programs and has noted differences in the ECTS (European Credit Transfer and Accumulation System) credit amount. Therefore courses determined by calculating the average credit based on their grade average credit courses credit courses in European Union were compared with the average in Turkey. This makes working with Erasmus students from courses taken at universities in European Union are aimed to draw attention to the difficulties faced in college he/she reads during pairing in Turkey.

Keywords: Data mining, Decision Trees, Naive Bayes, J48, Education, Computer Engineering Program

\section{Giriş}

Teknolojik alandaki gelişmelerle birlikte insanlar daha hızlı ve rahat bir şekilde işlemlerini yapabilmek için internet tabanlı uygulamaları daha çok tercih etmektedir. Bu durum daha fazla verinin dijital ortamda tutulmasına sebep olmuştur. Sürekli artan veriler işlenerek insanlar için faydalı bilgilerin elde edilmesi istenmiştir. Böylece veri madenciliğine ihtiyaç duyulmuştur.

Veri madenciliğinde büyük miktardaki veriler analiz edilmektedir. $\mathrm{Bu}$ veriler veri tabanlarında kullanıma uygun formatlarda tutularak, verilere hızlı şekilde ulaşılabilmesi sağlanmalıdır. Veri madenciliğiyle ilk bakışta ilişki kurulamayam veriler arasındaki ilişkilerin belirlenmesi hedeflenmektedir. Veri madenciliğiyle veri setleri arasındaki anlamsız ilişkiler, verilerin analiz yöntemleri ve çeşitli yazılım teknikleri kullanılarak elde edilmeye çalışılır (Akgöbek ve Çakır, 2019).

Veri madenciliği, çok büyük miktardaki ve çeşitli verilerin içindeki fark edilmemiş bilgilerin keşfedilerek bu bilgilerin gelecekle ilgili kararlarda daha sağlıklı ilerleyebilmek amacıyla kullanılmasıdır. Büyük ve anlamsız veriler kullanılarak, sonuçlar hakkında tahminde bulunulabilecek verileri elde edebilmek için bağlantı ve kuralların aranmadır. İlk bakışta bir anlam ifade etmeyen verilerin arasında bulunan ilişkikerin belirlenmesinde bilgisayar kullanılmaktadır (Dener vd., 2009).

Veri madenciliğgi, birçok sektör için büyük bir öneme sahiptir. Hizla artmakta olan verilerin analiz edilebilemesi ve elde edilen verilerin yorumlanabilmesi için ilişkisel veri tabanlarının kullanılması yeterli olmamıştır. Hızlı bir şekilde dijital ortamdaki verilerin artmasıyla birçok sektör veri madenciliğini kullanmak istemiştir. $\mathrm{Bu}$ durum büyük miktarlardaki verilerin otomatik olarak analiz edilebilmesi için akıllı analiz tekniklere ihtiyaca sebep olmuştur (Savas vd., 2012).

Veri madenciliği yapılarak elde edilen sonuçlar tek başına bir anlam ifade etmemesine rağmen çözüme ulaşabilmek için karar verilmesi gereken durumlarda karar süresinde yardım ederek problemin çözümünü kolaylaştımaktadır (Baykal, 2006).

Veri madenciliği ile anlamlı bir bilgi elde edilebilmesi için elimzide sağlıklı verilerin olması gerekmektedir. Bunun için veri madenciliği yapılmadan önce toplanan veriler üzerinde çeşitli işlemler yapılmaktadır. $\mathrm{Bu}$ işlemler aşağıdaki şekilde ifade edilebilir (Stolz vd., 2007):

- Verinin toplamas1

- Verinin temizlemesi ve dönüştürülmesi

- Modelin kurulması

- Modelin değerlendirilmesi

- Raporlama
İnternetin gelişmesiyle birlikte birçok alanda kullanılabilecek veriler elde edilmektedir. Bunun için veri madenciliğine birçok alanda ihtiyaç duyulmuştur. Veri madenciliğinden bankacılık, sağlık, mühendislik, iktisat, ekonomi, endüstri gibi alanlarda faydalanılmıştır. Bu çalışmada veri madenciliği eğitim alanındaki veriler üzerinde uygulanarak eğitim ile ilgili sonuçlar elde edilmiştir. Tablo 1'de 2006-2014 yılları arasında Türkiye'de gerçekleştirilen eğitim alanındaki veri madenciliği çalışmaları özetlenmiştir. Bu makalede ayrıca makale yazarlarının konu ile ilgili önceki çalışmalarına başvurulmuştır. $\mathrm{Bu}$ çalışmalar aşağıdaki gibi özetlenebilir:

- Türkiye'deki ve Avrupa'daki üniversitelerin bilgisayar mühendisliği lisans ders içerikleri karşılaştırılmıştır (Kilicer ve Samli, 2018).

- Türkiye'deki elektrik ve elektronik mühendisliği programındaki derslerin dağılımları incelenmiştir (Kilicer ve Samli, 2019).

- Türkiye'deki ve Çin'deki bilgisayar mühendisliği bölümleri karşılaştırılmıştır (Kilicer ve Samli, 2020).

\section{Materyal ve Metot}

\subsection{Verilerin Toplanması}

$\mathrm{Bu}$ çalışma için bilgisayar mühendisliği bölümü olan Türkiye'deki 80 üniversite incelenmiştir ve bilgisayar mühendisliği lisans programlarından 6835 ders listesi elde edilmiştir. Türkiye'deki üniversitelerin bilgisayar mühendisliği bölümü ile Erasmus programı anlaşması yaptığı Avrupa Birliği'ndeki 29 üniversitenin bilgisayar mühendisliği lisans programlarından 1220 dersten oluşan bir veri elde edilmiştir. Bu veriler üniversitelerin web sitelerinden elde edilmiştir. Bilgisayar mühendisliği web sayfalarına girilerek lisans ders listelerindeki ders bilgileri toplanmıştır. Üniversitelerin web sitelerinden ders bilgileri elde edilmesi sirasında ders isimlerine ek olarak dersin kredi bilgileri de toplanarak ders sınıflarının kredi kıyaslamasında kullanılmıştır. Aşağıda Türkiye'de üzerinde çalışılan 80 üniversite (alfabetik sırada) ve Avrupa Birliği'nde, üzerinde çalışılan üniversiteler (alfabetik sırada) ve bu üniversitelerin bulundukları ülkeler gösterilmiştir. Her üniversitenin web sitesinden veriler tek tek alındıktan sonra tüm veriler birleştirilmiştir. Verilerin birleştirilebilmesi için ilk olarak elde edilen veriler üzerinde veri temizleme, veri dönüştürme gibi işlemler yapılarak tüm veriler aynı formata ve düzenli bir şekle dönüştürülmüştür. Türkiye'deki üniveristelerin bilgisayar mühendisliği lisans bölümlerinden ve Erasmus anlaşması olduğu Avrupa Birliği’ndeki üniversitelerin bilgisayar mühendisliği lisans bölümlerinden ders isimleri kredi ya da AKTS bilgileri ve dersin zorunlu ya da seçmeli olması bilgileri toplanmıştır. Elde edilen veri kümesinde farklı üniversitelerden toplanan aynı isimli ve aynı koşullara sahip olan (kredi ve zorunlu-seçmeli olma 
durumu) derslerden bir tane kalacak şekilde tekrara sebep olan veriler temizlenmiştir. Bu durumda Türkiye'deki üniversitelerden elde edilen ders listesi sayısı 6835'ten 5527'ye düşmüştür. Aynı işlem Avrupa Birliği'ndeki üniversitelerden elde edilen veriler için de yapıldığında 1220 olan veri sayısı 1192 olmuştur. Elde edilen derslerin sınıflandırılabilmesi ve derslerin çeşitliliğinin analiz edilebilmesi için dersler "Temel Dersler, Matematik Dersleri, Yazılım Dersleri, Donanım Dersleri, Yapay Zeka Dersleri, Ağ Güvenlik Dersleri, Ek Dersler, Bölüm İçi Seçmeli Dersler, Bölüm Dışı Seçmeli Dersler" olmak üzere 9 sınıfa ayrılmıştır. Dersler sınıflara ayrılarak Türkiye'deki ve Avrupa Birliği'ndeki eğitimde ders çeşitliliğinin hangi alanlarda nasıl dağıldığı incelenerek Türkiye'de bilgisayar mühendisliği bölümünde artırılması gereken ders alanlarının belirlenmesi ve eğitim kalitesinin yükseltilmesi amacıyla önerilerde bulunulması hedeflenmiştir. Ayrıca belirlenen ders sınıflarına göre kredi ortalamaları incelenerek ders çeşitliliğine ek olarak derslerin kredi bilgisinde de değişikliklerin yapılarak derslere gereken önemin verilebilmesi hedeflenmiştir. Ayrıca kredi ve AKTS arasındaki farkın Erasmus programı ile Avrupa Birliği'ndeki bilgisayar mühendisliği programına giden öğrencilerin orada aldıkları dersleri geri geldiklerinde eşleştirebilmek için yaşadıkları sorunların gözlemlenebilmesi hedeflenmiştir.

\section{Tablo 1. Türkiye'de Ĕgitim Alanındaki Veri Madenciliği Çalışmaları}

\begin{tabular}{|c|c|c|c|c|}
\hline Yılı & Çalışma Alanı & Amaci & Kullandığı Algoritma(lar) & Kaynak \\
\hline 2006 & $\begin{array}{c}\text { Pamukkale Üniversitesi Eğitim } \\
\text { Fakültesi }\end{array}$ & KPSS sonuçlarının tahmin edilmesi & $\begin{array}{c}\text { Yapay Sinir Ağları, Regresyon } \\
\text { Analizi }\end{array}$ & (Özçınar, 2006) \\
\hline 2007 & Atatürk Üniversitesi & $\begin{array}{c}\text { mezun olunan lise türleri ile kazanılan } \\
\text { fakültelerin arasındaki ilişkinin tespit } \\
\text { edilmesi }\end{array}$ & Sınıflandırma Yöntemleri & (Ayık vd., 2007) \\
\hline 2007 & $\begin{array}{c}\text { Anadolu Üniversitesi Açıköğretim } \\
\text { Fakültesi }\end{array}$ & $\begin{array}{l}\text { bilgisayar kullanımı ve öğrenci başarısı } \\
\text { arasındaki ilişkinin incelenmesi }\end{array}$ & C5.0 Karar Ağacı, kNN & (Aydın,2007) \\
\hline 2011 & çeşitli kız meslek liseleri & $\begin{array}{c}\text { öğrencilerde başarısızlıklara neden olan } \\
\text { etkenlerin incelenmesi }\end{array}$ & kNN, K-Medoids & (Birt1l, 2011) \\
\hline 2011 & Selçuk Üniversitesi & $\begin{array}{c}\text { öğrencilerle hakkında gelecekle ilgili tahmin } \\
\text { yapılabilmesi için gerekli birliktelik kuralları } \\
\text { çıarılması }\end{array}$ & $\begin{array}{c}\text { Apriori Algoritması, Karar } \\
\text { Ağaçları }\end{array}$ & (Ekim, 2011) \\
\hline 2011 & çeşitli dershaneler & $\begin{array}{c}\text { dershaneki eğitim programına göre } \\
\text { üniversiteye yerleşme durumlarının } \\
\text { incelenmesi }\end{array}$ & $\begin{array}{c}\text { Karar Ağaçları, Bayes } \\
\text { Sınıflandırıcıları, Birliktelik } \\
\text { Kuralları, Apriori Algoritması }\end{array}$ & (Hatipoğlu vd., 2011) \\
\hline 2012 & üniversite giriş sınavına girenler & $\begin{array}{l}\text { üniversiteye giriş sınavında öğrencilerin } \\
\text { başarılarının tahmin edilmesi }\end{array}$ & Naive Bayes Algoritması & (Göker, 2012) \\
\hline 2012 & meslekî eğitim alanlar & $\begin{array}{c}\text { meslekî eğitimin öğrenci başarısına etkisinin } \\
\text { ortaya çıkartılması }\end{array}$ & kNN, C5.0 Karar Ağacı & (Yelegin, 2012) \\
\hline 2012 & $\begin{array}{c}\text { Cumhuriyet Üniversitesi Sosyal } \\
\text { Bilimler Enstitüsü } \\
\end{array}$ & $\begin{array}{c}\text { ögrrencilerin ders notlarını etkileyen } \\
\text { faktörlerin tespit edilmesi }\end{array}$ & SimpleCART Algoritması & (Alan, 2012) \\
\hline 2012 & $\begin{array}{l}\text { Gazi Üniversitesi Teknik Eğitim } \\
\text { Fakültesi } \\
\end{array}$ & $\begin{array}{c}\text { öğrenci başarısını etkileyen faktörlerin } \\
\text { incelenmesi }\end{array}$ & $\begin{array}{l}\text { CRT, CHAID, Yapay Sinir } \\
\text { Ağları, Apriori, kNN }\end{array}$ & (Kurt ve Erdem, 2012) \\
\hline 2013 & Firat Üniversitesi Eğitim Fakültesi & $\begin{array}{c}\text { öğrencilerin mezuniyet notlarının tahmin } \\
\text { edilmesi }\end{array}$ & $\begin{array}{c}\text { Yapay Sinir Ağları, Karar } \\
\text { Ağaçları }\end{array}$ & (Şengür, 2013) \\
\hline 2013 & $\begin{array}{c}\text { Kocaeli Üniversitesi Temel Bilgi } \\
\text { Teknolojileri Kullanımı dersini } \\
\text { alanlar }\end{array}$ & $\begin{array}{l}\text { öğrencilerin bilgisayar okuryazarlığını } \\
\text { etkileyen faktörlerin etkisinin tespit edilmesi }\end{array}$ & $\begin{array}{l}\text { Min-Max Normalleştirme, } \\
\text { ZScore normalleştirme }\end{array}$ & (Çoban Budak, 2013) \\
\hline 2013 & $\begin{array}{c}\text { Ankara Üniversitesi Eğitim Bilimleri } \\
\text { Fakültesi ile Dil ve Tarih-Coğrafya } \\
\text { Fakültesi }\end{array}$ & $\begin{array}{l}\text { yükseköğretimde öğrenci başarılarının } \\
\text { sınıflandırılması }\end{array}$ & $\begin{array}{l}\text { Yapay Sinir Ağları, Lojistik } \\
\text { Regresyon Analizi }\end{array}$ & (Çırak ve Çokluk, 2013) \\
\hline 2013 & Fırat Üniversitesi & $\begin{array}{l}\text { öğrencilerin akıllı tahtaya ilişkin } \\
\text { tutumlarının incelenmesi }\end{array}$ & Apriori Algoritmas1 & (Hark, 2013) \\
\hline 2014 & $\begin{array}{l}\text { İstanbul ilinde } 2011 \text { yılındaki LYS } \\
\text { sinavına giren liseliler }\end{array}$ & $\begin{array}{l}\text { LYS başarılarına göre okul } \\
\text { performanslarının incelenmesi }\end{array}$ & CHAID Algoritması & (Bilen vd., 2014) \\
\hline 2014 & $\begin{array}{c}\text { Ankara Yasemin Karakaya Bilim ve } \\
\text { Sanat Merkezi’nde öğrenim gören } \\
\text { yaşları üstün yetenekliler }\end{array}$ & $\begin{array}{l}\text { üstün yetenekli öğrencilerin ilgi alanlarının } \\
\text { analizi }\end{array}$ & JRip algoritması & (Çöllüoğlu Gülen, 2014) \\
\hline 2014 & $\begin{array}{l}\text { Karabük Üniversitesi Mühendislik } \\
\text { Fakültesi Uzaktan Eğitim Bölümleri }\end{array}$ & $\begin{array}{l}\text { mühendislik fakültesi uzaktan eğitim } \\
\text { bölümlerinin analizi }\end{array}$ & Lojistik Regresyon Analizi & (Taşdelen, 2014) \\
\hline 2014 & $\begin{array}{l}\text { Cumhuriyet Üniversitesi İktisadi ve } \\
\text { İdari Bilimler Fakültesi }\end{array}$ & öğrenci verilerinin sınıflandırılması & LADTree Algoritması & (Alan, 2014) \\
\hline 2014 & $\begin{array}{c}\text { Hacettepe Üniversitesi Bilgisayar ve } \\
\text { Öğretim Teknolojileri Eğitimi } \\
\text { bölümü }\end{array}$ & $\begin{array}{c}\text { çevrimiçi öğrenme ortamındaki etkileşim } \\
\text { verilerine göre öğrencilerin } \\
\text { performanslarının modellenmesi }\end{array}$ & $\mathrm{kNN}$ & (Akçapınar, 2014) \\
\hline
\end{tabular}


Türkiye'de incelenen üniversiteler şunlardır;

1. Abant İzzet Baysal Üniversitesi

2. Abdullah Gül Üniversitesi

3. Akdeniz Üniversitesi

4. Alanya Alaaddin Keykubat Üniversitesi

5. Amasya Üniversitesi

6. Anadolu Üniversitesi

7. Ankara Üniversitesi

8. Antalya Bilim Üniversitesi

9. Atatürk Üniversitesi

10. Atılım Üniversitesi

11. Avrasya Üniversitesi

12. Bahçeşehir Üniversitesi

13. Balıkesir Üniversitesi

14. Başkent Üniversitesi

15. Batman Üniversitesi

16. Beykent Üniversitesi

17. Bursa Teknik Üniversitesi

18. Bülent Ecevit Üniversitesi

19. Cumhuriyet Üniversitesi

20. Çanakkale Onsekiz Mart Üniversitesi

21. Çankaya Üniversitesi

22. Doğuş Üniversitesi

23. Dokuz Eylül Üniversitesi

24. Dumlupınar Üniversitesi

25. Düzce Üniversitesi

26. Ege Üniversitesi

27. Erciyes Üniversitesi

28. Eskişehir Osmangazi Üniversitesi

29. Fatih Sultan Mehmet Üniversitesi

30. F1rat Üniversitesi

31. Galatasaray Üniversitesi

32. Gazi Üniversitesi

33. Hitit Üniversitesi

34. Işık Üniversitesi

35. İnönü Üniversitesi

36. İstanbul Arel Üniversitesi

37. İstanbul Aydın Üniversitesi

38. İstanbul Gelişim Üniversitesi

39. İstanbul Sabahattin Zaim Üniversitesi

40. İstanbul Şehir Üniversitesi

41. İstanbul Üniversitesi

42. İstanbul Teknik Üniversitesi

43. İzmir Ekonomi Üniversitesi

44. Kadir Has Üniversitesi

45. Karabük Üniversitesi

46. Karadeniz Teknik Üniversitesi

47. Kastamonu Üniversitesi

48. Kocaeli Üniversitesi

49. Muğla Sitkı Koçman Üniversitesi

50. Namık Kemal Üniversitesi

51. Necmettin Erbakan Üniversitesi

52. Nişantaşı Üniversitesi

53. Okan Üniversitesi

54. Ortadoğu Teknik Üniversitesi

55. Özyeğin Üniversitesi

56. Pamukkale Üniversitesi
57. Sakarya Üniversitesi

58. Selçuk Üniversitesi

59. Siirt Üniversitesi

60. Süleyman Demirel Üniversitesi

61. Sütçü İmam Üniversitesi

62. TOBB Ekonomi ve Teknoloji Üniversitesi

63. Trakya Üniversitesi

64. Üsküdar Üniversitesi

65. Bozok Üniversitesi

66. Hasan Kalyocu Üniversitesi

67. Mersin Üniversitesi

68. Yıldız Teknik Üniversitesi

69. Boğaziçi Üniversitesi

70. Harran Üniversitesi

71. Marmara Üniversitesi

72. Yıldırım Beyazıt Üniversitesi

73. Bilkent Üniversitesi

74. Hacettepe Üniversitesi

75. Yeditepe Üniversitesi

76. Manisa Celal Bayar Üniversitesi

77. Bilecik Şeyh Edebali Üniversitesi

78. Gebze Teknik Üniversitesi

79. Maltepe Üniversitesi

80. Yalova Üniversitesi

Avrupa Birliği’nde incelenen üniversiteler şunlardır;

1. 1 Decembrie 1918" University Of Alba Iulia (Romanya)

2. Agh University Of Science And Technology (Polonya)

3. Fachhochschule Landshut - Hochschule Für Wirtschaft - Sozialwesen - Technik (Almanya)

4. Fh Joanneum University Of Applied Sciences (Avusturya)

5. Freie Universitaet Berlin (Almanya)

6. Halmstad University (İsveç)

7. Lodz University Of Technology (Polonya)

8. Paris Ix Dauphine (Fransa)

9. Politecnico De Coimbra (Portekiz)

10. Polytechnic Institute Of Guarda (Portekiz)

11. Polytechnic Institute of Viana do Castelo (Portekiz)

12. Rezekne Academy Of Technology Latvia (Letonya)

13. Riga Technical University (Letonya)

14. Technical University Of Ostrava (Çek Cumhuriyeti)

15. Technical University-Sofia (Bulgaristan)

16. Th Mittelhessen (Almanya)

17. Universida De Lisboa (Portekiz)

18. Universidad De Murcia (İspanya)

19. Universita Degli Studi Del Sannio (İtalya)

20. University Of Beira Interior (Portekiz)

21. University Of Bradford (İngiltere)

22. University Of Groningen (Hollanda)

23. University Of Koblenz Landau (Almanya)

24. University Of Piraeus (Yunanistan)

25. University Of Ruse (Bulgaristan) 
26. Universitat Politechnica De Catalunya-Barselona Tech (İspanya)

27. Warsaw University Of Technology (Polonya)

28. Wroclaw University Of Technology (Polonya)

29. Wsb-Technicka Univerzita Ostrava (Çek Cumhuriyeti)

\subsection{Kullanılan Algoritmalar}

Bu çalışmada verilerin sınıflandırılması ve elde edilen sonuçların değerlendirilmesi için Weka platformu kullanılmıştır. Weka platformu içerisinde bulunan ve sınıflandırma konusunda başarılı sonuçların elde edilmesini sağlayan algoritmalardan Naive Bayes ve J48 algoritmaları verilerin sinıflandırılmasında tercih edilmiştir.

\subsubsection{Naive Bayes Algoritması ile Türkiye'deki ve Avrupa Birliği'ndeki Ders Dă̆ılımının Tespit Edilmesi}

Naive Bayes algoritması bir veri kümesindeki değerlerin frekanslarını sayarak bir olasılık kümesini hesaplayan bir olasılıksal sınıflandırıcıdır. Bayes algoritması, sınıf değişkeninin değeri göz önüne alındığında tüm özniteliklerin bağımsız olduğunu varsayar (Patil ve Sherekar, 2013).

Naive Bayes algoritmasının önemli avantajlarından biri parametrelerin tahmin edilmesinde fazla eğitim verisine ihtiyaç duymamaktadır (Farhad Alam ve Pachauri, 2017).

Veri madenciliği kullanılarak sınıflandırma yapılırken ilk olarak sistem eğitilmelidir. Bu çalıșmada veri seti oluşturulurken Türkiye'deki üniversitelerden elde edilen derslerin isimleri, kredi bilgileri, zorunlu-seçmeli olma bilgisi kullanılmıştır. Elde edilen bu verilerin bir kısmı eğitim verisi olarak ayrışmış ve bu eğitim seti Weka platformuna eklenerek sistem önce eğitilmiştir. Eğitim verilerinde veri setindeki her dersin ait olduğu sınıf bilgisi eklenerek sisteme dersler ve sınıf bilgileri arasındaki ilişki öğretilmiştir. Şekil 1'de Türkiye'deki ders listesinden elde edilen verilerden eğitim için kullanılan verilerin Weka platformuna yüklenmiş hali görülmektedir.

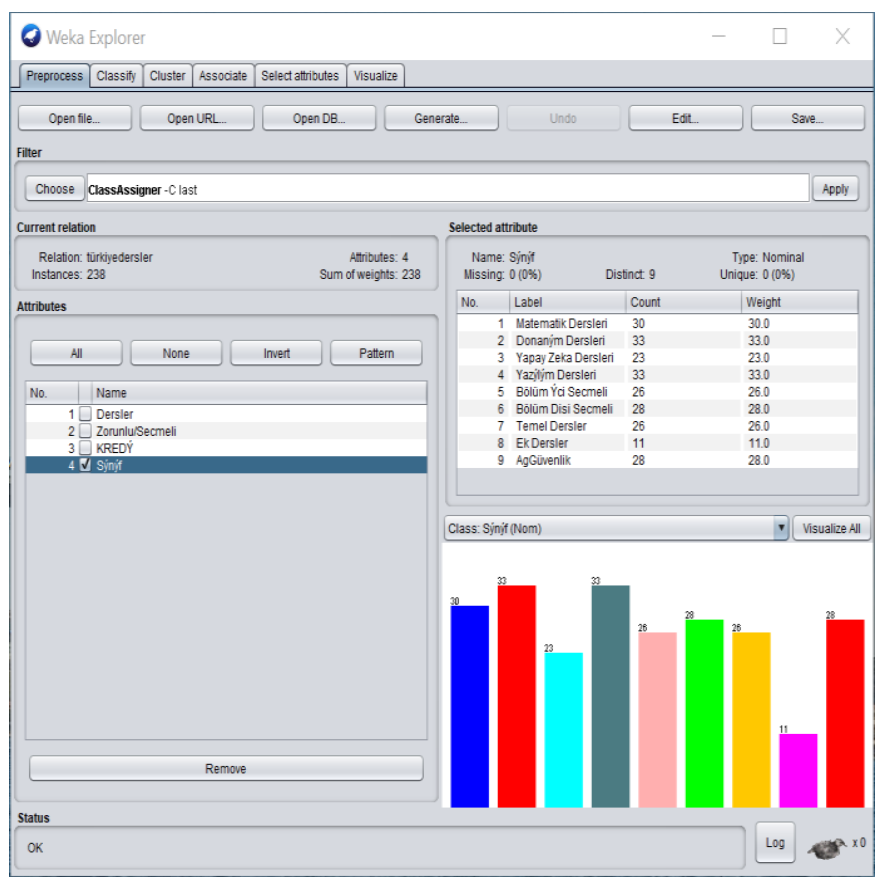

Sisteme eğitim verileri yüklendikten sonraki adımda bu verilerin hangi algoritma kullanılarak eğitileceği belirlenmelidir. Eğitim için algoritmanın belirlenmesi Şekil 2'de görülmektedir.



Şekil 2. Türkiye'deki Dersler İçin Sınıflandırma Algoritmasının Seçilmesi - Naive Bayes

Weka platformuna eğitim verileri eklenerek program çalıştırıldığında \%98,7'lik bir başarı elde edilmiştir. Şekil 3'te eğitim verilerinin uygun algoritma seçilerek çalıştırılmış hali görülmektedir.

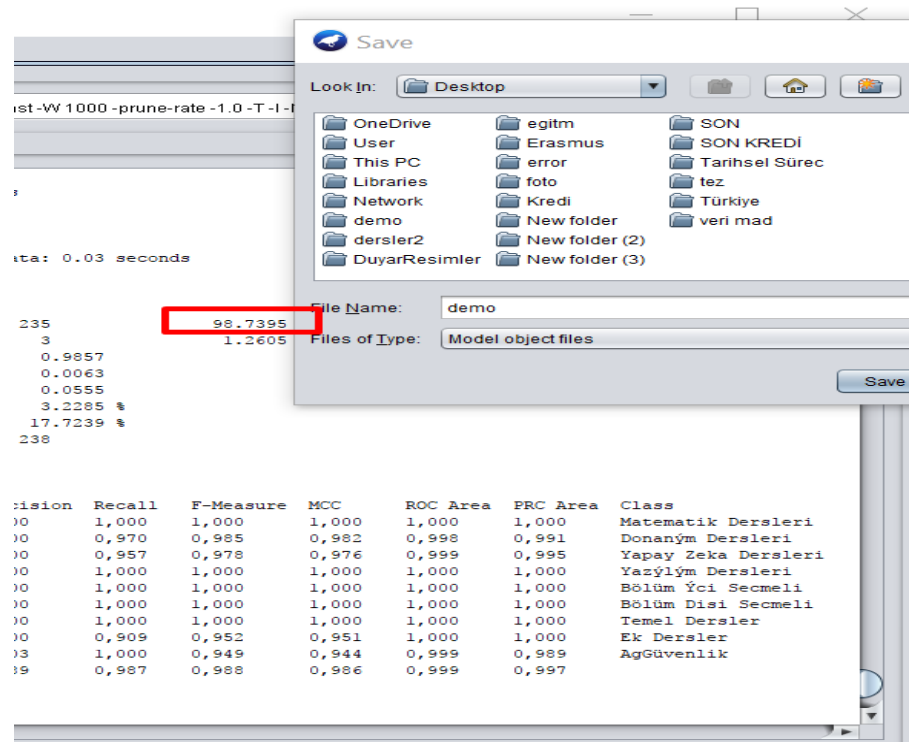

Şekil 3. Türkiye'deki Dersler Iç̧in Eğitim Dosyasının Çalıştırılması - Naive Bayes

Sistem için eğitim işlemi tamamlandıktan sonra derslerin sınıflarını belirleyebilmek için tüm veriler sisteme yüklenmektedir. Şekil 4'te Türkiye'deki derslerin Naive Bayes algoritmasına göre sisteme yüklendikten sonra derslerin sınıflarının belirlenmesi görülmektedir.

Şekil 1. Türkiye'deki Ders Listesinin Yüklenmesi 


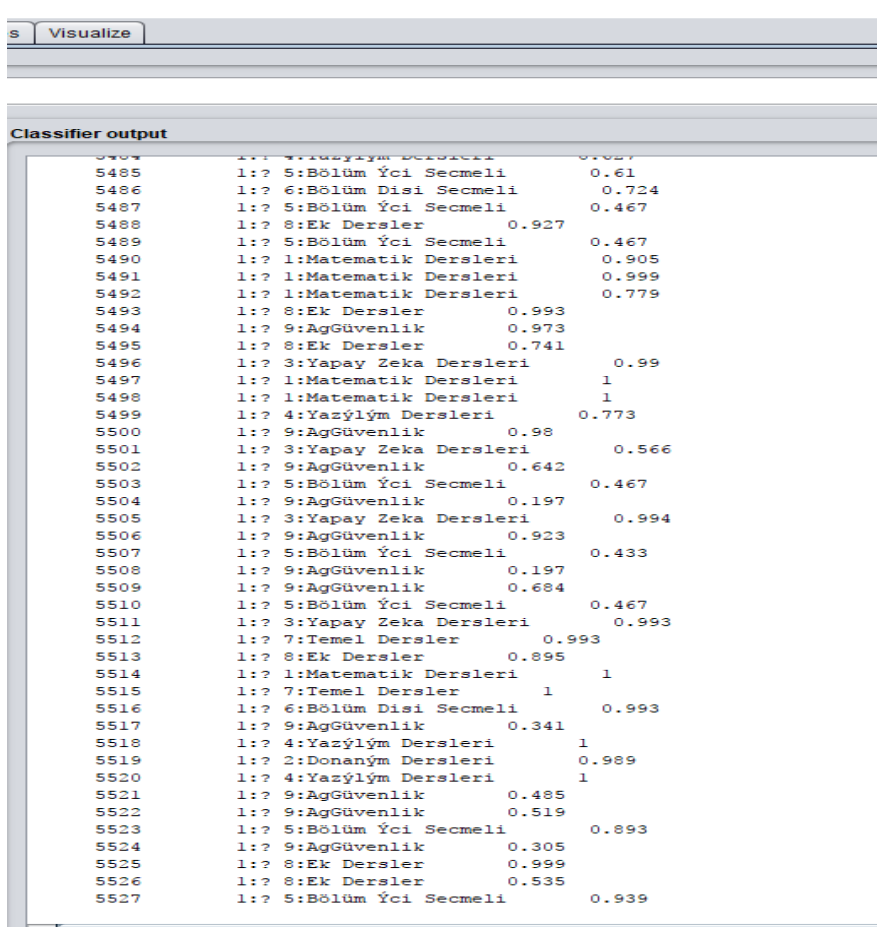

\section{Şekil 4. Türkiye'deki Derslerin Sinfflandırılması}

Naive Bayes algoritması kullanılarak Türkiye'deki bilgisayar mühendisliği lisans programlarından elde edilen derslerin sinıflandırılmasından sonra bu üniversitelerin Erasmus anlaşmasına sahip olduğu Avrupa Birliği'ndeki bilgisayar mühendisliği lisans programlarından elde edilen verilerin derslerin ismi, AKTS bilgisi ve zorunlu-seçmeli olduğu bilgisi alınarak oluşturulan veriler ile de aynı işlemler yapılmıştır. Şekil 5 'te Avrupa Birliği'ndeki üniversitelerden elde edilen verilerin Naive Bayes algoritması kullanılarak sınıflandırılması sonucunda derslerin sınıf bilgisi görülmektedir.

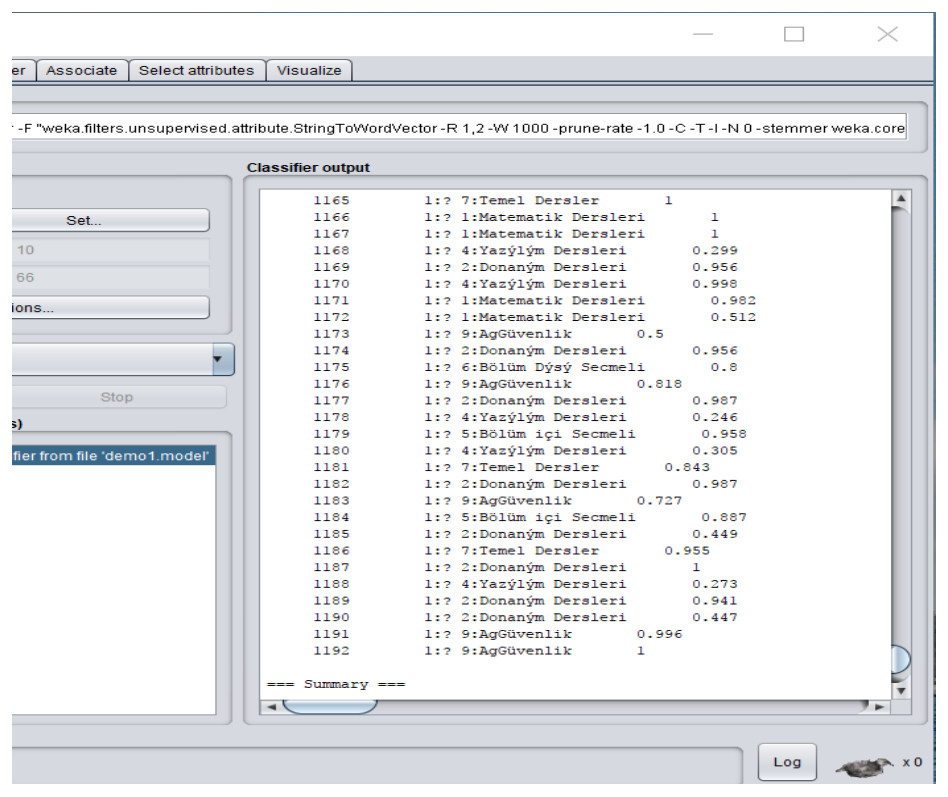

Şekil 5. Avrupa Birliği’ndeki Derslerin Sınıflandırılması

\subsubsection{J48 Algoritmast ile Türkiye'deki ve Avrupa Birliği’ndeki Ders Dağılımının Tespit Edilmesi}

Karar ağacı algoritmaları bilgi temsil etmek için kullanılan klasik yollardan biridir. Karar ağacı algoritmalarıla veriler özyinelemeli şekilde sınıflandırılır. Karar ağacı algoritmaları kullanılarak veri yapıları hızlı bir şekilde ifade edilir (Nizam ve Akın, 2014). Bir karar ağacının iç düğümleri farklı nitelikleri gösterirken düğümler arasındaki dallar ise bu özelliklerin gözlemlenen örneklerde sahip olabileceği olası değerleri verir. Terminal düğümler ise bağımlı değişkenlerin son sınıfını gösterir. $\mathrm{Bu}$ algoritma hedef sınıf için entropi değerini hesaplar ve daha sonra tahmin edici sınıf için bilgi değerini hesaplar ve bilgi kazanımını hesaplar. $\mathrm{Bu}$ hesaplamalardan en yüksek bilgi kazanımını sağlayan sınıf tespit edilir (Farhad Alam ve Pachauri, 2017). Karar ağaçları verilerden basit sınıflandırma modeli oluşturmayı amaçlar. Ağaç üzerinde ilerlerken bir yolu seçer ve alternatif yollar içinden daha iyi olabilecek çözümleri kaçırabilir. J48 algoritması J48 karar ağacı algoritmasının Weka platformundaki java uygulamasıdır (Altınkardeş vd., 2012).

Naive Bayes algoritması kullanılarak verilerin sınıflandırma işlemi tamamlandıktan sonra başka bir algoritma ile aynı işlem tekrarlanarak algoritma seçimi konusunda emin olabilmek ve farklı algoritmaları kıyaslayabilmek için Türkiye'deki ve Avrupa Birliği'ndeki üniversitelerden elde edilen veriler J48 algoritması kullanılarak incelenmiştir.

Türkiye'deki ve Avrupa Birliği'ndeki üniversitelerden elde edilen bilgisayar mühendisliği lisans derslerinin sınıflandırılmasında ilk olarak eğitim dosyası sisteme yüklenerek, sistem J48 algoritmasına göre eğitilmiştir. Eğitim sonundaki başarı oranı $\%$ 75,6 olarak elde edilmiştir. Şekil 6'da eğitim sonunda elde edilen başarı oranı görülmektedir.

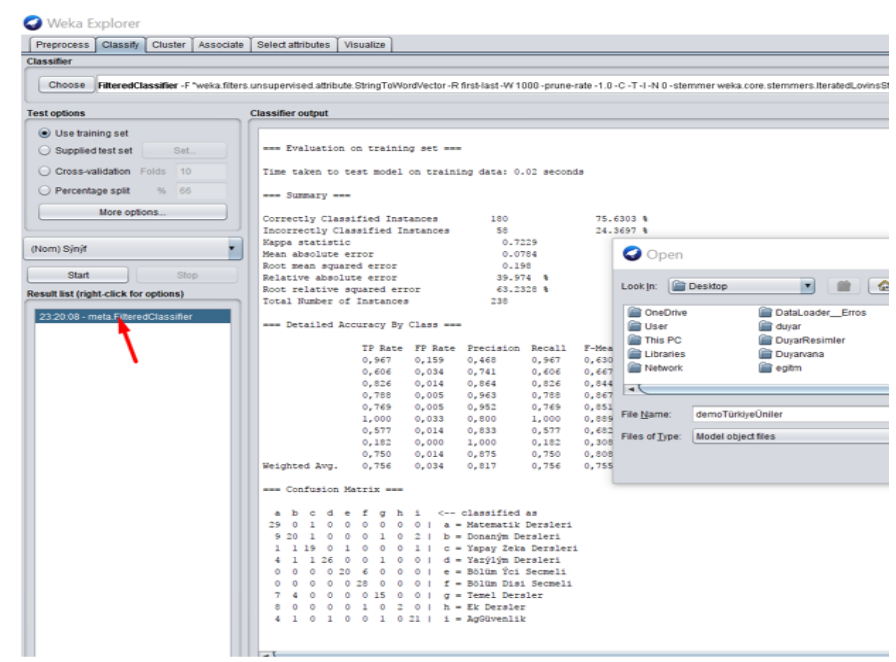

\section{Şekil 6. Türkiye'deki Dersler İçin Eğitim Dosyasının Çalıştırılması}

Sistem eğitimi tamamlandıktan sonra Naive Bayes algoritmasında olduğu gibi önce Türkiye'deki üniversitelerin bilgisayar mühendisliği lisans programlarından elde edilen tüm veriler daha sonra da Avrupa Birliği'ndeki üniversitelerin bilgisayar mühendisliği lisans programlarından elde edilen tüm veriler sisteme yüklenerek J48 algoritması kullanılarak her dersin ait olduğu sınıf belirlenmeye çalışılmıştır. 


\subsubsection{Naive Bayes Algoritmast ile Türkiye'deki ve Avrupa Birliği'ndeki Ders Kredisinin Dă̆ılımının Tespit Edilmesi}

Türkiye'deki ve Avrupa Birliği'ndeki üniversitelerden verilerin toplanmasında derslerin kredi ve AKTS sayıları arasındaki fark dikkat çekmiştir. Bu durum Erasmus programından faydalanan öğrenciler için ders eşitlenmesi sırasında bir zorluk oluşturduğu tahmin edilmektedir. Ayrıca öğrenciler için dersin önemini belirleyen ders kredilerinin sınıflara göre dağılımının nasıl olduğu inceleyebilmek için veri madenciliği ile kredilerin dağılımları da incelenemiştir.

Ders kredilerinin incelenmesinde doğruluk oranı daha yüksek olan Naive Bayes algoritması kullanılarak elde edilen Türkiye'deki bilgisayar mühendisliği lisans programları ve Avrupa Birliği’ndeki bilgisayar mühendisliği lisans programları derslerinin sınıflara göre dağılımları kullanılmıştır. Veri madenciliğiyle derslerin sınıf bilgileri bulunması sırasında derslerin kredi bilgileri de hazırlanan veri dosyasında bulunmaktadır. Naive Bayes algoritması kullanılarak elde edilen Türkiye'deki bilgisayar mühendisliği lisans ders sınıflarına ait olan derslerin kredi bilgileri kullanılarak her sinıfin ortalama kredi oranları bulunmuştır. Aynı şekilde Avrupa Birliği’ndeki bilgisayar mühendisliği lisans ders sınıflarına ait olan derslerin kredi bilgileri kullanılarak her sınıfın ortalama kredi oranları bulunmuştur.

\section{Araştırma Sonuçları ve Tartışma}

$\mathrm{Bu}$ çalışmada Türkiye'deki bilgisayar mühendisliği lisans programlarından ve Avrupa Birliği ülkelerindeki bilgisayar mühendisliği lisans programlarından elde edilen ders verileri Naive Bayes algoritmas1 ve J48 algoritması kullanılarak sınıflandırılmıştır. Türkiye'deki ve Avrupa Birliği'ndeki üniversiterlerdeki derslerin ders sınıflarına göre dağılımları incelenmiştir. Ayrıca bu çalışmada Naive Bayes algoritması kullanılarak yapılan sınıflandırmaya göre ders sınıflarının kredi ve AKTS değilımları incelenmiştir

Tablo 2'de Naive Bayes algoritması kullanılarak Türkiye'deki bilgisayar mühendisliği lisans programlarından elde edilen derslerin belirlenen sınıflara göre dağılımları görülmektedir.

Tablo 2. Naive Bayes Algoritmasına Göre Türkiye'deki Derslerin Dağılımı

\begin{tabular}{|l|c|c|}
\hline \multicolumn{1}{|c|}{ Ders Sınıfi } & Ders Adedi & Oran (\%) \\
\hline Matematik Dersleri & 556 & 10,05 \\
\hline Donanım Dersleri & 600 & 10,85 \\
\hline Yazıllım Dersleri & 992 & 17,94 \\
\hline Yapay Zeka Dersleri & 640 & 11,57 \\
\hline Ă̆ Güvenlik Dersleri & 487 & 8,81 \\
\hline Bölüm İ̧̧i Seçmeli Dersler & 134 & 2,42 \\
\hline Bölüm Dışı Seçmeli Dersler & 982 & 17,76 \\
\hline Temel Dersler & 481 & 8,70 \\
\hline Ek Dersler & 655 & 11,85 \\
\hline TOPLAM & $\mathbf{5 5 2 7}$ & $\mathbf{1 0 0}$ \\
\hline
\end{tabular}

Tablo 3'te ise Naive Bayes algoritması kullanılarak Avrupa Birliği'ndeki bilgisayar mühendisliği lisans programlarından elde edilen derslerin belirlenen sınıflara göre dağılımları görülmektedir.
Tablo 3. Naive Bayes Algoritmasına Göre Avrupa Birliği’ndeki Derslerin Dă̆glımı

\begin{tabular}{|l|c|c|}
\hline \multicolumn{1}{|c|}{ Ders Sınıfi } & Ders Adedi & Oran (\%) \\
\hline Matematik Dersleri & 156 & 13,08 \\
\hline Donanım Dersleri & 206 & 17,28 \\
\hline Yazılım Dersleri & 260 & 21,81 \\
\hline Yapay Zeka Dersleri & 75 & 6,29 \\
\hline Ăg Güvenlik Dersleri & 100 & 8,38 \\
\hline Bölüm İçi Seçmeli Dersler & 71 & 5,95 \\
\hline Bölüm Dışı Seçmeli Dersler & 149 & 12,5 \\
\hline Temel Dersler & 115 & 9,64 \\
\hline Ek Dersler & 60 & 5,03 \\
\hline TOPLAM & 1192 & 100 \\
\hline
\end{tabular}

Naive Bayes algoritması ile yapılan işlemler daha sonra J48 algoritması da kullanılarak yapılmıştır. Tablo 4'te J48 algoritması kullanılarak Türkiye'deki bilgisayar mühendisliği lisans programlarından elde edilen derslerin belirlenen sınıflara göre dağılımları görülmektedir.

Tablo 4. J48 Algoritmasına Göre Türkiye'deki Derslerin Dağılımı

\begin{tabular}{|l|c|c|}
\hline \multicolumn{1}{|c|}{ Ders Sinıfi } & Ders Adedi & Oran (\%) \\
\hline Matematik Dersleri & 630 & 11,39 \\
\hline Donanım Dersleri & 642 & 11,61 \\
\hline Yazılım Dersleri & 926 & 16,75 \\
\hline Yapay Zeka Dersleri & 470 & 8,5 \\
\hline Ăg Güvenlik Dersleri & 914 & 16,53 \\
\hline Bölüm İçi Seçmeli Dersler & 621 & 11,23 \\
\hline Bölüm Dışı Seçmeli Dersler & 383 & 6,92 \\
\hline Temel Dersler & 428 & 7,74 \\
\hline Ek Dersler & 513 & 9,28 \\
\hline TOPLAM & 5527 & 100 \\
\hline
\end{tabular}

Tablo 5'de ise J48 algoritması kullanılarak Avrupa Birliği’ndeki bilgisayar mühendisliği lisans programlarından elde edilen derslerin belirlenen sınıflara göre dağılımları görülmektedir Tablo 5. J48 Algoritmasına Göre Avrupa Birliği'ndeki Derslerin
Dağılımı

\begin{tabular}{|l|c|c|}
\hline \multicolumn{1}{|c|}{ Ders Sınıfı } & Ders Adedi & Oran (\%) \\
\hline Matematik Dersleri & 156 & 13,08 \\
\hline Donanım Dersleri & 206 & 17,28 \\
\hline Yazılım Dersleri & 260 & 21,81 \\
\hline Yapay Zeka Dersleri & 75 & 6,29 \\
\hline Ağ Güvenlik Dersleri & 100 & 8,38 \\
\hline Bölüm İçi Seçmeli Dersler & 71 & 5,95 \\
\hline Bölüm Dışı Seçmeli Dersler & 149 & 12,5 \\
\hline Temel Dersler & 115 & 9,64 \\
\hline Ek Dersler & 60 & 5,03 \\
\hline TOPLAM & 1192 & 100 \\
\hline
\end{tabular}

Naive Bayes algoritmasına göre elde edilen sınıflara göre Türkiye'deki üniversitelerin ve Avrupa Birliği’ndeki 
üniversitelerin ders kredilerinin ortalaması sırasıyla Tablo 6'da ve Tablo 7'de görülmektedir.

Tablo 6. Naive Bayes Algoritmasına Göre Türkiye'deki Kredi Ortalaması

\begin{tabular}{|l|c|}
\hline \multicolumn{1}{|c|}{ Ders Sınıfi } & Kredi Ortalaması \\
\hline Matematik Dersleri & 3,41 \\
\hline Donanım Dersleri & 3,17 \\
\hline Yazılım Dersleri & 3,1 \\
\hline Yapay Zeka Dersleri & 3,12 \\
\hline Ăg Güvenlik Dersleri & 3,12 \\
\hline Bölüm İçi Seçmeli Dersler & 2,89 \\
\hline Bölüm Dışı Seçmeli Dersler & 2,6 \\
\hline Temel Dersler & 3,22 \\
\hline Ek Dersler & 2,61 \\
\hline
\end{tabular}

Tablo 7. Naive Bayes Algoritmasına Göre Avrupa Birliği’ndeki Kredi Ortalamasl

\begin{tabular}{|l|c|}
\hline \multicolumn{1}{|c|}{ Ders Sınıfi } & Kredi Ortalaması \\
\hline Matematik Dersleri & 5,52 \\
\hline Donanım Dersleri & 5,42 \\
\hline Yazılım Dersleri & 5,58 \\
\hline Yapay Zeka Dersleri & 4,9 \\
\hline Ăğ Güvenlik Dersleri & 5,34 \\
\hline Bölüm İçi Seçmeli Dersler & 4,19 \\
\hline Bölüm Dışı Seçmeli Dersler & 4,29 \\
\hline Temel Dersler & 5,66 \\
\hline Ek Dersler & 3,08 \\
\hline
\end{tabular}

Türkiye'deki ve Avrupa Birliği'ndeki bilgisayar mühendisliği lisans programlarından elde edilen verilerin Naive bayes algoritması ile belirlenen sınıflara göre dağılımlarını daha net bir şekilde görebilmek için Şekil 7 ve Şekil 8'de görülen grafikler kullanılmıştır.

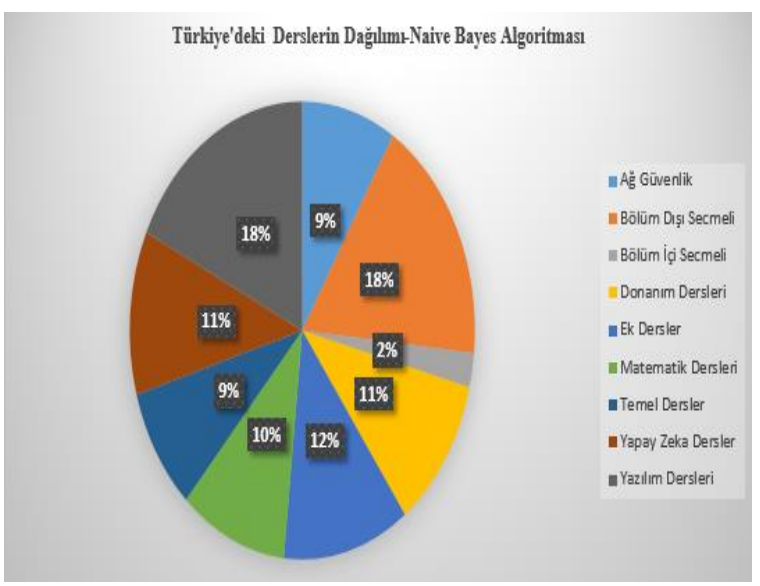

Şekil 7. Naive Bayes Algoritmasına Göre Türkiye'deki Derslerin Dă̆llımı



Şekil 8. Naive Bayes Algoritmasına Göre Avrupa Birliği’ndeki Derslerin Dă̆ılımı

Türkiye'deki ve Avrupa Birliği’ndeki üniversitelerin bilgisayar mühendisliği bölümlerinden elde edilen derslerin J48 algoritması kullanılarak ders sınıflarına göre dağılımlarını gösteren dairesel grafikler Şekil 9 ve Şekil 10’da görülmektedir.

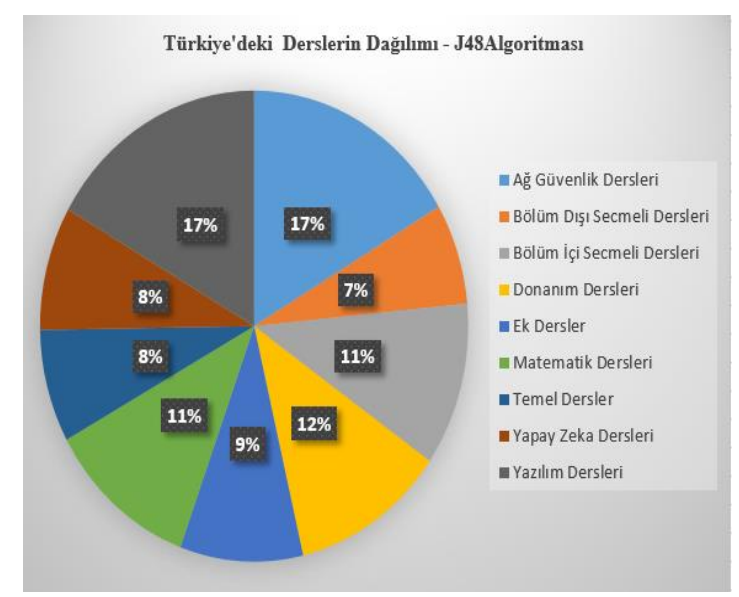

Şekil 9. J48 Algoritmasına Göre Türkiye'deki Derslerin Dağılımı



Şekil 10. J48 Algoritmasına Göre Avrupa Birliği'ndeki Derslerin Dağılımı

Naive Bayes algoritması kullanılarak yapılan sınıflandırmaya göre elde edilen sinıfların kredi ortalamasının daha rahat görülebilmesi için Şekil 11'deki ve Şekil 12'deki grafikler kullanılmıştır. 


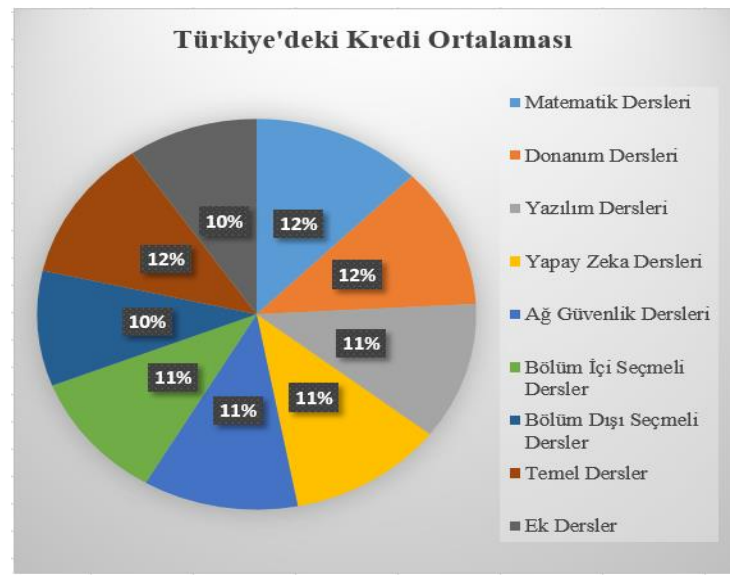

Şekil 11. Naive Bayes Algoritmasına Göre Türkiye'deki Kredi Ortalamasl



Şekil 12. Naive Bayes Algoritmasına Göre Avrupa'daki Kredi Ortalamasl

Türkiye'deki ve Avrupa'daki ders sınıflarına ait kredi ortalamalarının daha net görülerek karşılaştırabilmek için Şekil 13'teki grafik kullanılmıştır.



Şekil 13. Kredilerin Karşılaştırılması

\section{Sonuç}

$\mathrm{Bu}$ çalışmada, veri madenciliği ile Türkiye'deki üniversitelerde verilen bilgisayar mühendisliği lisans dersleri çeşitliliği ile Avrupa Birliği'ndeki bilgisayar mühendisliği lisans dersleri çeşitliliği kıyaslanmıştır. Bu çalışma Türkiye'deki üniversitelerin ikili programlar yürüttüğü Avrupa Birliği’ndeki üniversiteler ile arasındaki eğitim farklarının belirlenmesi ve eksiklikler için çeşitli çözüm önerileri getirilmesi hedeflenmiştir. $\mathrm{Bu}$ çalışmanın yapılmasındaki bir diğer amaç ise, Türkiye'deki üniversitelerde okuyan öğrencilerin Erasmus programı ile Avrupa Birliği'ndeki üniversitelerden aldıkları dersleri saydırmak istediklerinde yaşadıkları problemleri azaltabilmek ve ders eşitlemesinin adil bir şekilde yapılabilmesini sağlayabilmektir.

$\mathrm{Bu}$ çalışmada daha önce yapılan eğitim alanında yapılan veri madenciliği çalışmaları incelenmiştir. Veri madenciliği çalışmalarında sıklıkla tercih edilen Weka platformu tercih edilmiş ve sınıflandırma algoritmaları olarak Naive Bayes ve J48 algoritmaları kullanılmıştır. Elimizdeki verilerle daha iyi sonuç elde edebileceğimiz iki algoritma seçilmiştir ve elde edilen sonuçların her iki algoritma sonuçları dikkate alınarak kıyaslanmıştır.

Yapılan çalışmalar sonucunda elde edilen sonuçlar şu şekilde özetlenebilir:

- Mühendislik eğitiminde ve iş hayatında önemli bir yeri olan Matematik Dersleri sınıfının çeşitliliği Naive Bayes ve J48 algoritmanın sonucuna göre de Avrupa Birliği'ndeki ülkelere göre daha düşüktür.

- Yazılım Dersleri, Donanım Dersleri ve Temel Dersler sınıflarındaki ders çeşitliliği her iki algoritmanın sonucuna göre de Avrupa Birliği’ndeki ülkelere göre daha düşüktür.

- Ek Dersler sınıfına ait derslerin çeşitliliği her iki algoritmaya göre de Türkiye'de Avrupa Birliği’ndeki ülkelere göre daha yüksektir.

- Öğrencilerin kendi ilgi alanına göre derslere yönelmesini sağlayan Bölüm İçi Seçmeli Derslerin çeşitliliği Naive Bayes algoritmasına göre Avrupa Birliği'nde Türkiye'deki oranın 3 katı kadardır. Ancak J48 algoritmasına göre ise Türkiye'deki Bölüm İçi Ders çeşitliliğinin Avrupa Birliği’ndeki ders çeşitliliğinden daha fazla olduğu görülmüştür.

- Bölüm D1şı Seçmeli Derslerin çeşitliliği Naive Bayes algoritmasına göre ülkemizde daha yüksektir ancak J48 algoritmasına göre ise Bölüm Dışı Seçmeli Derslerin çeşitliliği Avrupa Birliği’nde daha yüksektir.

- Yapay Zeka Dersleri çeşitliliği ve Ağ Güvenliği Dersleri çeşitliliği her iki algoritmaya göre de ülkemizde Avrupa Birliği'ne göre daha yüksektir.

Öğrencilerin dersin önemini kıyasladıkları ve derslere verecekleri önemi belirlemelerinde etkili olduğunu düşünülen kredi oranlarının belirlenen ders sınıflarına göre dağılımları incelendiğinde ise Türkiye'deki ve Avrupa Birliği’ndeki bilgisayar mühendisliği lisans derslerine ait olan ders sınıflarının kredi ortalamaları ve AKTS ortalamaları kıyaslandığında bütün ders sınıflarında kredi ortalamalarının büyük bir oranda düşük olduğu görülmektedir. Ayrıca Türkiye'deki ders sınıflarının kredi ortalamalarının birbirine yakın olduğu görülmektedir. Bu durum öğrenci gözünden incelendiğinde derslerin aynı seviyede görülmesi ve birbirinin yerine konulabilecek şekilde 
algılanabilmesine sebep olabileceği düşünülmektedir. Ayrıca derslerin kredi oranlarının bu şekilde düşük olması öğrencinin derse yeterli özeni göstermesinde engel olacağı düşünülmektedir.

Bu makalede günümüzün oldukça önemli bir sorunu olan eğitim konusu ele alınmıştır. İlerideki çalışmalarda farklı bölümler için veri setleri ve farklı sınıflandırma algoritmaları kullanılarak pek çok faydalı çalışma yapılması hedeflenmektedir.

\section{Kaynakça}

Akçapınar, G. (2014). Çevrimiçi Öğrenme Ortamındaki Etkileşim Verilerine Göre Öğrencilerin Akademik Performanslarının Veri Madenciliği Yaklaşımı İle Modellenmesi, Hacettepe Üniversitesi Eğitim Bilimleri Enstitüsü, Doktora Tezi.

Akgöbek, Ö., Çakır, F., (2009). Veri Madenciliğinde Bir Uzman Sistem Tasarımı, Akademik Bilişim'09 - XI. Akademik Bilişim Konferansı Bildirileri Harran Üniversitesi, Şanlıurfa.

Alan, M. A. (2012). Veri Madenciliği Ve Lisansüstü Öğrenci Verileri Üzerine Bir Uygulama. Dumlupınar Üniversitesi Sosyal Bilimler Dergisi, (33), 165-174.

Alan, M.A. (2014). Karar Ağaçlarıyla Öğrenci Verilerinin Sınıflandırılması. Atatürk Üniversitesi İktisadi ve İdari Bilimler Dergisi, 28(4), 101-112 .

Altınkardeş, A., Erdal, H., Fevzi BABA, F. ve Fak, S.,A. (2012). ABPM Ölçümü olmaksızın karar ağaçları algoritması ile Non- Dipper/Dipper Öngörüsü, 6.Ulusal Tıp Bilişimi Kongresi, Antalya.

Aydın, S. (2007). Veri Madenciliği Ve Anadolu Üniversitesi Uzaktan Eğitim Sisteminde Bir Uygulama, Anadolu Üniversitesi / Sosyal Bilimler Enstitüsü, Doktora Tezi.

Ayık, Y. Z., Özdemir, A. ve Yavuz, U. (2007). Lise Türü Ve Lise Mezuniyet Başarısının, Kazanılan Fakülte İle İlişkisinin Veri Madenciliği Tekniği İle Analizi. Atatürk Üniversitesi Sosyal Bilimler Enstitüsü Dergisi, 10(2), 441-454.

Baykal, A. (2006). Veri Madenciliği Uygulama Alanları. Dicle Üniversitesi Ziya Gökalp Eğitim Fakültesi Dergisi, 7, 95-107.

Bırtıl, F. S. (2011). Kız Meslek Lisesi Öğrencilerinin Akademik Başarısızlık Nedenlerinin Veri Madenciliği Tekniği İle Analizi, Afyon Kocatepe Üniversitesi Fen Bilimleri Enstitüsü, Yüksek Lisans Tezi.

Bilen, Ö., Hotaman, D., Aşkın, Ö. E. ve Büyüklü, A.H. (2014). LYS Başarılarına Göre Okul Performanslarının Eğitsel Veri Madenciliği Teknikleriyle İncelenmesi: 2011 İstanbul Örneği. Eğitim ve Bilim, 39(172), 78-94.

Çırak, G. ve Çokluk, Ö. (2013). Yükseköğretimde Öğrenci Başarılarının Sınıflandırılmasında Yapay Sinir Ağları ve Lojistik Regresyon Yöntemlerinin Kullanılması. Mediterranean Journal of Humanities, 3(2), 71-79.

Çoban Budak, E. (2013). Üniversite Öğrencileri İçin Bilgisayar Okuryazarlığını Etkileyen Faktörlerin Etkisinin Veri Madenciliği İle Analizi. AJIT-e-Online Academic Journal Of Information Technology, 4(11), 1-14.

Çöllüoğlu Gülen, Ö. (2014). Veri Madenciliği Teknikleri İle Üstün Yetenekli Öğrencilerin İlgi Alanlarının Analizi, Gazi Üniversitesi Bilişim Enstitüsü, Doktora Tezi.
Dener, M., Dörterler, M., Orman, A., (2009,Şubat). Açık Kaynak Kodlu Veri Madenciliği Programları: Weka'da Örnek Uygulama”, Akademik Bilişim'09 - XI. Akademik Bilişim Konferansı Bildirileri, Harran Üniversitesi, Şanlıurfa.

Ekim, U. (2011). Veri Madenciliği Algoritmalarını Kullanarak Öğrenci Verilerinden Birliktelik Kurallarının Çıkarılması. Selçuk Üniversitesi Fen Bilimleri Enstitüsü, Yüksek Lisans Tezi.

Farhad Alam, F. ve Pachauri, S. (2017). Comparative Study of J48, Naive Bayes and One-R Classification Technique for Credit Card Fraud Detection using WEKA. Advances in Computational Sciences and Technology, 10(6 ), 1731-1743.

Göker, H. (2012). Üniversite Giriş Sınavında Öğrencilerin Başarılarının Veri Madenciliği Yöntemleri İle Tahmin Edilmesi, Gazi Üniversitesi Bilişim Enstitüsü, Yüksek Lisans Tezi.

Hark, C. (2013). Öğrencilerin Akıllı Tahtaya İlişkin Tutumlarının İncelenmesine Yönelik Bir Veri Madenciliği Uygulaması. Fırat Üniversitesi Eğitim Bilimleri Enstitüsü, Yüksek Lisans Tezi.

Hatipoğlu, B., Aslan, Z., Zontul, M. ve Güneş, A. (2011). Dershane Eğitiminin, Öğrencinin Üniversiteye Yerleşmesindeki Etkisi. İstanbul Aydın Üniversitesi Dergisi, 3(12), 13-50.

Kılıçer, S., ve Şamlı, R. (2018). Veri Madenciliği ile Türkiye'deki ve Avrupa Birliği Ülkelerindeki Bilgisayar Mühendisliği Bölümleri Ders İçeriklerinin Karşılaştırılması. İstanbul Üniversitesi, Fen Bilimleri Enstitüsü, Yüksek Lisans Tezi.

Kilicer, S. Ve Şamlı, R (2018). Comparison of Turkey ad European Union Computer Engineering Programs", ICATCES - International Conference on Advanced Technologies, Computer Engineering and Science, Karabük/TÜRKIYE

Kilicer, S. Ve Şamlı, R (2019). Veri Madenciliği İle Türkiye'deki Elektrik Elektronik Mühendisliği Programlarının Karşılaştırılması", HEZARFEN - International Congress of Science, Mathematics and Engineering Sciences, İzmir/TÜRKIYYE

Kilicer, S. Ve Şamlı, R (2020). Türkiye ve Çin Bilgisayar Mühendisliği Programlarının Karşılaştırılması”, EFIS Geleceğin Mühendisleri Uluslararası Öğrenci Sempozyumu, Zonguldak/Türkiye

Kurt, Ç. ve Erdem, O. A. (2012). Öğrenci Başarısını Etkileyen Faktörlerin Veri Madenciliği Yöntemleriyle İncelenmesi. Politeknik Dergisi, 15(2), 111-116.

Nizam, H., Akın, S.,S.,(2014). Sosyal Medyada Makine Öğrenmesi ile Duygu Analizinde Dengeli ve Dengesiz Veri Setlerinin Performanslarının Karşılaştırılması, XIX Türkiye'de İnternet Konferansı, Yaşar Üniversitesi, İzmir.

Özçınar, H. (2006). KPSS sonuçlarının veri madenciliği yöntemleriyle tahmin edilmesi. Pamukkale Üniversitesi Fen Bilimleri Enstitüsü, Yüksek Lisans Tezi.

Patil, T. Sherekar, S. (2013). Performance Analysis of Naive Bayes and J48 Classification Algorithm for Data Classification. International Journal Of Computer Science And Applications, 6(2), 256-261. 
Savas, S., Topaloglu, N., Yılmaz, M. (2012). Veri Madenciliği ve Türkiye'deki Uygulama Örnekleri. İstanbul Ticaret Üniversitesi Fen Bilimleri Dergisi, 11(21), 1-23.

Stolz, H., Lehmann, P., ve Poonnawa, W., (2007). Data Mining with Microsoft SQL Server 2005, International DSI / Asia and Pacific DSI 2007.

Şengür, D. (2013). Öğrencilerin Akademik Başarılarının Veri Madenciliği Metotları İle Tahmini, Fırat Üniversitesi Eğitim Bilimleri Enstitüsü, Yüksek Lisans Tezi

Taşdelen, A. (2014). Veri Madenciliği Yöntemleri İle Mühendislik Fakültesi Uzaktan Eğitim Bölümlerinin Analizi: Karabük Üniversitesi Örneği, Karabük Üniversitesi Fen Bilimleri Enstitüsü, Yüksek Lisans Tezi.

Yelegin, A. (2012). Mesleki Eğitimde Öğrenci Altyapısının Öğrenci Eğitim Başarısına Etkisinin Veri Madenciliği Yöntemleriyle Ortaya Çıkartılması. Yayınlanmamış Yüksek Lisans Tezi, Beykent Üniversitesi, İstanbul.- 